\title{
Bibliografia comentada sobre políticas públicas para formação de professores*
}

\author{
Natália A. Morato Fernandes
}

Marinalva Vieira Barbosa

BARBOSA, Marinalva Vieira; GONÇALVES, Amanda Regina; GAYDECZKA, Beatriz et al. (Org.). A boniteza de ensinar e a identidade do professor na contemporaneidade. Campinas: Mercado de Letras, 2015.

Coletânea de textos resultantes de palestras e conferências do IV Encontro Nacional das Licenciaturas e do III Seminário Nacional do Pibid, realizados na Universidade Federal do Triângulo Mineiro (UFTM), em 2013. Na "Nota de abertura", Antonio Nóvoa comenta que a Carta de Uberaba, "Em defesa da identidade e profissionalização docente", estabelece um continuum entre a formação inicial e a formação continuada, e, para completá-lo, é necessário incluir uma fase de transição entre a formação e a profissão. Contrariamente às outras profissões, que concedem uma atenção particular a esses anos, os professores iniciantes são "lançados" nas escolas sem qualquer acompanhamento ou apoio. Na primeira parte do livro são apresentadas questões sobre: formação inicial e continuada de professores; pesquisa na formação e na prática docente; estudos de caso de experiências didático-pedagógicas; educação do campo; avaliação

\footnotetext{
* Nossos agradecimentos à equipe de professores da Universidade Federal do Triângulo Mineiro (UFTM), pesquisadores do projeto "Impactos das ações do Pibid nas escolas de Uberaba-MG", financiado pela Fundação de Amparo à Pesquisa do Estado de Minas Gerais (Fapemig), que nos ajudou na seleção e comentário desta bibliografia comentada: Amanda Regina Gonçalves, Fernanda Borges de Andrade, Flávio Henrique Dias Saldanha, Janaína Aguiar Mendes Galvão, Maíra Sueco M. Córdula, Juliana Bertucci Barbosa, Nilva Lúcia Lombardi Sales, Vera Lúcia Bonfim Tiburzio.
} 
educacional; políticas para o ensino superior; didática, metodologias e objetos de aprendizagem; violência na escola; e medicalização da educação. Na segunda parte, encontra-se o percurso de organização e realização desses dois eventos, com reflexões das organizadoras sobre os diversos processos vivenciados e as escolhas e motivações para torná-los experiências formativas.

DUARTE, Raphael de Leão. A formação de professores de geografia da rede estadual de ensino no município de Aquidauana/MS: ensaios sobre o Pacto Nacional pelo Fortalecimento do Ensino Médio. 2016. 92 f. Dissertação (mestrado em Geografia) - Universidade Federal de Mato Grosso do Sul, campus de Aquidauana, Mato Grosso do Sul, 2016. Disponível em: < https://sistemas.ufms.br/sigpos/portal/trabalhos/ download/2494/cursoId:205>.

A pesquisa tem como objetivo analisar o processo de desenvolvimento e implementação do Pacto Nacional pelo Fortalecimento do Ensino Médio em Aquidauana, estado do Mato Grosso do Sul, destacando aspectos positivos e críticos relacionados à formação proposta, bem como os reflexos na prática docente dos professores de geografia participantes desse programa. A metodologia de pesquisaação possibilitou acompanhar os profissionais de educação envolvidos em todos os encontros do Pacto. Para a coleta de dados, além da observação e aplicação de entrevistas e questionários, foi realizada uma pesquisa documental com base na legislação afeta ao ensino médio e nos índices de rendimento escolar disponibilizados pelo Ministério da Educação (MEC), Instituto Nacional de Estudos e Pesquisas Educacionais Anísio Teixeira (Inep) e Secretaria de Estado de Educação (SED). Embora o Pacto signifique um avanço para a valorização do profissional de educação, existem lacunas a serem superadas, principalmente no que se refere à necessidade de ampliação dos debates que envolvem metodologias de ensino, identidade docente e realidade escolar.

FREITAS, Helena Costa Lopes de. A (nova) política de formação de professores: a prioridade postergada. Educação \& Sociedade, Campinas, v. 28, n. 100, p. 12031230, out. 2007. Disponível em: < http://www.scielo.br/pdf/es/v28n100/a2628100>.

O artigo contextualiza as políticas de formação de professores implementadas no início dos anos 2000 e focaliza as ações do governo federal para o período de 2006-2010, em particular o fortalecimento da Universidade Aberta do Brasil (UAB) e a nova Coordenação de Aperfeiçoamento de Pessoal de Nível Superior (Capes) como agência reguladora da formação de professores. Na primeira metade da década, destaca-se o caráter emergencial das ações para a formação docente, privilegiando formações aligeiradas em detrimento da construção de uma efetiva política 
de formação de professores e valorização do magistério como profissão. As ações do Pró-Licenciatura, da UAB e da Capes caracterizam-se pela estratégia de formação continuada e em serviço, por meio de programas de educação a distância, aliada à utilização de novas tecnologias. Quanto à participação das instituições de educação superior nesses programas, salienta-se a perda de autonomia didático-científica na concepção dos projetos estabelecidos em âmbito nacional. Na parte final, é apresentada a nova configuração da Capes para atuação em programas de qualificação docente do ensino básico e algumas hipóteses acerca do que poderia vir a ser sua atuação no contexto exposto.

GATTI, Bernadete; SILVA JUNIOR, Celestino A. da; MIZUKAMI, Maria da Graça N. et al. (Org.). Por uma revolução no campo da formação de professores. São Paulo: Unesp, 2015.

Coletânea de palestras apresentadas no XII Congresso Estadual Paulista sobre Formação de Educadores e no II Congresso Nacional de Formação de Professores, em que são abordados temas como: políticas de formação inicial docente, participação de profissionais da escola na formação de professores, valorização do conhecimento docente, espaços e processos de formação, relação universidade-escola, estágios supervisionados e residência educacional. O capítulo de encerramento resgata a temática do duplo congresso para afirmar que esta deve ser tomada em sua acepção rigorosa, de transformação radical nos valores e procedimentos praticados na formação de professores, a fim de superar os atuais limites, como a petrificação dos processos formativos e a pouca diversificação da legislação educacional e, especificamente, a de formação de professores.

LIMA, Sara Passos de. Os paradigmas atuais da formação docente: olhares sobre o Pibid. 2015. 198 f. Dissertação (mestrado em Educação) - Universidade Federal de Rondônia (Unir), 2015. Disponível em: < http://www.mestradoeducacao.unir.br/ downloads/4531_dissertacao_versao_oficial_site_sara_passos.pdf $>$.

Para investigar em quais aspectos o Programa Institucional de Bolsa de Iniciação à Docência (Pibid) contribuiu para a formação inicial dos ex-bolsistas no período de 2009 a 2013, foi utilizada a abordagem qualitativa/exploratória e, para a coleta de dados, questionários, entrevistas e análise documental. Os sujeitos da pesquisa foram oito alunas egressas do curso de química e ex-participantes do Pibid, dois coordenadores de área e duas supervisoras do Pibid-Química da Universidade Federal de Rondônia (Unir). Constatou-se que a proposta de formação está pautada no paradigma da prática-reflexiva, diferentemente do modelo apresentado pelo currículo do curso de química. Assim, o Pibid é um norteador para 
o desenraizamento da racionalidade técnica presente no curso de licenciatura, entretanto, há alguns limitantes, como: 1) não haver um prazo para a continuidade do Pibid, ou seja, pode ser encerrado a qualquer momento; e, 2) não dar acesso a todos os estudantes de licenciatura, pois os aspectos positivos promovidos pelo programa em um curto espaço de tempo são fundamentais para a (re)construção da carreira docente e do ensino de química.

LINDINO, Terezinha C.; PINTO, Marcelo B.; MALLMANN, Erika R.S. A formação continuada do docente do ensino médio frente a implantação de programas institucionais federativos. Pleiade, Foz do Iguaçu, PR, v. 10, n. 19, p. 23-30, jan./jun. 2016. Disponível em: < http://intranet.uniamerica.br/site/revista/index.php/pleiade/ article/viewFile/321/281>.

Para se compreender a implantação de programas institucionais federativos de formação continuada, como o Pacto Nacional pelo Fortalecimento do Ensino Médio (PNEM), são analisadas duas ações estratégicas que estão articuladas com essa modalidade: o redesenho curricular, em desenvolvimento nas escolas por meio do Programa Ensino Médio Inovador (ProEMI), e a Formação Continuada de Professores do Ensino Médio, que tem como objetivo promover a valorização da formação continuada de professores e coordenadores pedagógicos que atuam no ensino médio público, nas áreas rurais e urbanas, em consonância com a Lei no 9.394/96 e as Diretrizes Curriculares Nacionais do Ensino Médio. Segundo o PNEM, essas ações têm por objetivo a melhoria da qualidade da educação e a implantação das Diretrizes Curriculares Nacionais para o Ensino Médio, documento que aponta o trabalho, a cultura, a ciência e a tecnologia como dimensões do ensino médio que deverão integrar os conhecimentos das diferentes áreas do currículo nesse nível de ensino.

LOPES, Roberta Gleyciângela Souza. Mudanças no letramento acadêmico de cursistas do Profletras: questões de linguagem e identidade. 2016. 296 f. Dissertação (mestrado em Linguística) - Universidade Federal do Ceará, Fortaleza, 2016. Disponível em: $<$ http://www.repositorio.ufc.br/handle/riufc/22154?mode=full $>$.

De que modo o mestrado profissional, como uma nova modalidade de formação continuada, exerce influência nos processos identitários dos professores, conduzindo a mudanças discursivas e possíveis mudanças de ação? Para responder a essa questão, a pesquisa fundamenta-se nos estudos sociais do letramento e na Análise de Discurso Crítica, e analisa dados qualitativos de professores da educação básica inscritos no Programa de Mestrado Profissional em Letras (Profletras). Foram descritos os eventos de letramento do mestrado profissional para relacioná-los às práticas de letramento, que, por sua vez, envolvem dimensões sociais e culturais, como valores, atitudes, sentimentos e relações sociais. O significado identificacional foi 
analisado por meio das categorias modalidade e avaliação, ambas relacionadas ao comprometimento dos professores com suas proposições. A análise indicou que a incursão em práticas de leitura/escrita/discussão de textos propiciadas pelo mestrado profissional contribuiu para mudanças significativas no letramento acadêmico dos sujeitos pesquisados e, no contexto dessas mudanças, há redefinição e reconstrução das identidades sociais, definidas pela Análise de Discurso Crítica como os "eus" associados a domínios e a instituições específicas.

LUCACHINSKI, Elci Schroeder. Pacto Nacional pela Alfabetização na Idade Certa: a formação de professores para a prática alfabetizadora com alunos com deficiência. 2015. 185 f. Dissertação (mestrado em Educação) - Universidade Comunitária da Região de Chapecó (Unochapecó), 2015. Disponível em: <http://www.uniedu. sed.sc.gov.br/wp-content/uploads/2016/03/Disserta\%C3\%A7\%C3\%A3o-ElciSchroeder-Lucachinski.pdf $>$.

A formação proposta pelo Pacto Nacional pela Alfabetização na Idade Certa (PNAIC) foi analisada a fim de se conhecer as relações entre o que é proposto nos documentos e o que é vivenciado na formação, considerando a orientação da prática alfabetizadora com alunos com deficiência da rede municipal de ensino de Chapecó, no estado de Santa Catarina. A coleta de dados fez-se mediante análise documental, observação participante, conversas informais e entrevistas semiestruturadas com 48 professores da turma de formação onde aconteceu a observação, dos quais foram entrevistadas 13 professoras, além de uma coordenadora pedagógica e um formador, ambos atuantes no nível estadual. Os dados foram tratados com base na análise de conteúdo temática, aliada à hermenêutica dialética. Os sentidos atribuídos pelas professoras à alfabetização de alunos com deficiência estão permeados por distintas concepções e marcados por significações produzidas no processo de formação no âmbito do PNAIC e/ou de outros processos formativos. Quanto aos conhecimentos que podem auxiliar a prática com esses alunos, a maioria das professoras refere que, mesmo que a formação não tenha articulado os conteúdos com essa prática, elas conseguiram individualmente relacioná-los a partir de reflexões realizadas durante os encontros, porém enfatizam que isso poderia ter sido trabalhado coletivamente. Todas elas ou não se lembram dos cadernos específicos da educação especial ou dizem conhecê-los superficialmente. As contribuições da formação para a prática com alunos com deficiência consistem no reconhecimento da importância tanto das atividades lúdicas para o trabalho pedagógico diferenciado quanto da reflexão sobre a prática e no estabelecimento da relação entre teoria e prática.

MANZANO, Thaís Sodré. Formação continuada de professores alfabetizadores do Pacto Nacional pela Alfabetização na Idade Certa (PNAIC) no Município de São Paulo: proposições e ações. 2015. 127 f. Dissertação (mestrado em Educação) Pontifícia Universidade Católica de São Paulo, 2015. Disponível em: < https://tede2. pucsp.br/handle/handle/10463>. 
A hipótese é a de que os professores têm pouca autonomia nos processos de formação continuada, nos quais são privilegiadas ações formativas hegemônicas, que não apenas desconsideram as culturas dos professores - e, com isso, suas práticas e concepções - como também as regulam. Foram analisados os documentos oficiais do programa referentes à formação continuada de professores e realizadas entrevistas com participantes dos processos de formação em 2013, no município de São Paulo. A análise dos dados permitiu concluir que o Pacto Nacional pela Alfabetização na Idade Certa (PNAIC) é um programa educacional cuja concepção de formação de professores alfabetizadores revela-se ultrapassada e autoritária, e sua implementação no município de São Paulo tem sido a expressão do modelo de Estado regulador, sendo a formação de professores alfabetizadores caracterizada mais como reguladora de práticas do que promotora do desenvolvimento profissional docente. Observou-se uma clara separação entre aqueles que discutiram e elaboraram os materiais, suas referências curriculares e pedagógicas e quem os aplicou. As concepções de formação de professores e de alfabetização e letramento presentes no PNAIC convergem para um mesmo ideal de sociedade e indivíduo, no qual a formação, profissional ou elementar, é essencial para formatar e sujeitar os indivíduos (professores e alunos) a um modelo de gestão governamental por meio da regulação social.

MOURAZ, Ana; LEITE, Carlinda; FERNANDES, Preciosa. A formação inicial de professores em Portugal decorrente do Processo de Bolonha: uma análise a partir do "olhar" de professores e de estudantes. Revista Portuguesa de Pedagogia, Coimbra, n. 46-2, p. 189-209, 2012. Disponível em: < http://iduc.uc.pt/index.php/rppedagogia/ article/view/1744/1120>.

As autoras identificam uma alteração do modelo de formação anterior, analisando, por meio das percepções de professores, órgãos de direção e estudantes, os efeitos resultantes do modelo imposto pós-Bolonha. Discutem inicialmente as orientações das políticas de formação do modelo anterior, no qual afirmam encontrar uma integração entre a formação específica da área do saber científico e a formação didático-pedagógica, coexistentes nos cursos para professores em formação inicial. A Declaração de Bolonha (1999) originou novas políticas de formação docente. Uma de suas premissas é assegurar maior qualificação, uma vez que a formação de professores, atualmente, corresponde ao nível de mestrado, porém essa mudança não resultou em maior tempo dedicado à formação didático-pedagógica nem em maior inserção dos estudantes em situações profissionais pré-exercício. Foram identificadas categorias segundo três dimensões relacionadas ao modelo de formação: a caracterização do modelo e vantagens e desvantagens resultantes; as condições de sua implementação; os desafios com os quais se deparam alunos 
e professores. Como conclusão, apontam, por um lado, o retrocesso ao modelo bietápico de formação docente e, por outro lado, a opção por formações generalistas.

SAUL, Ana Maria; SAUL, Alexandre. Contribuições de Paulo Freire para a formação de educadores: fundamentos e práticas de um paradigma contra-hegemônico. Educar em Revista, Curitiba, Brasil, n. 61, p. 19-35, jul./set. 2016. Disponível em: < http:// www.scielo.br/pdf/er/n61/1984-0411-er-61-00019.pdf > .

A proposta de formação permanente de Paulo Freire é apresentada como um paradigma contra-hegemônico, capaz de reagir criticamente aos modelos dominantes de formação. Os autores expõem um panorama das críticas que vêm sendo feitas às políticas e práticas de formação de educadores e às racionalidades subjacentes às propostas que disputam projetos nesse campo de estudos e pesquisas. Na sequência, o paradigma de formação permanente de Paulo Freire, posto em ação na Secretaria de Educação do município de São Paulo (1989-1992), é discutido como uma possibilidade para construir, coletivamente, novas formas de agir e pensar na formação docente, em uma perspectiva crítico-transformadora. Por fim, são apontados resultados da pesquisa "Paulo Freire na atualidade: legado e reinvenção", que busca evidenciar a materialidade e a reinvenção do seu pensamento, em diferentes contextos educativos da realidade brasileira, no eixo da formação docente.

SAVIANI, Dermeval. Formação de professores: aspectos históricos e teóricos do problema no contexto brasileiro. Revista Brasileira de Educação, Rio de Janeiro, v. 14, n. 40, p. 143-155, jan./abr. 2009. Disponível em: < http://dx.doi.org/10.1590/ S1413-24782009000100012 >

Na primeira parte, o autor introduz o enfoque histórico e examina a trajetória da formação de professores no Brasil, desdobrando-a em seis períodos, de 18271890 até 1996-2006. Na segunda, são identificados dois modelos de formação de professores, que coexistem e são contrapostos: o dos conteúdos culturaiscognitivos, no qual a formação se esgota na cultura geral e no domínio específico de conteúdos da área de conhecimento correspondente à disciplina que será lecionada; e o pedagógico-didático, o qual considera que a formação do professor propriamente dita só se completa com o efetivo preparo pedagógico-didático. Na conclusão, propõe que a educação deveria ser tomada como máxima prioridade, definindo-a como o eixo de um projeto de desenvolvimento nacional, que carreasse para ela todos os recursos disponíveis, buscando com isso desencadear e promover um círculo virtuoso de desenvolvimento social, econômico e político. 
SILVA, Luciene Fernanda da. Coordenadores de área do Pibid: um olhar sobre o desenvolvimento profissional. 2015. 154 f. Dissertação (mestrado em Ensino de Física) - Programa Interunidades em Ensino de Ciências, Universidade de São Paulo, 2015. Disponível em: < http://www.teses.usp.br/teses/disponiveis/81/81131/ tde-21082015-165925/pt-br.php > .

O Programa Institucional de Bolsa de Iniciação à Docência (Pibid) tem como principal característica a aproximação entre a universidade e a escola de educação básica. Tal parceria é concretizada por meio de subprojetos dos quais fazem parte licenciandos, professores das escolas (supervisores) e professores de instituições de ensino superior (IES) - os coordenadores de área. O estudo concentra-se nos coordenadores de área de subprojetos Pibid que envolvem cursos de licenciatura em física de IES públicas do estado de São Paulo e busca responder à seguinte questão: Quais são os impactos da participação no Pibid para o desenvolvimento profissional de coordenadores de área de subprojetos que envolvem cursos de licenciatura em física? Entrevistas semiestruturadas foram realizadas com 11 coordenadores de área. O instrumento utilizado para a coleta de dados teve como base contribuições de diversos autores, as quais foram sintetizadas em seis dimensões do desenvolvimento profissional e adequadas para o coordenador de área do Pibid: carreira acadêmica e profissional, atualização científica e profissional, condução de ensino, sustentação da aprendizagem, gestão universitária e imagem dos sujeitos.

224 Os dados foram apresentados por meio de análises narrativas organizadas em quatro categorias que emergiram desses dados: a parceria universidade-escola, as articulações com a pesquisa, a relação com a instituição universitária e os impactos na própria prática como formador de professores. A análise revelou que a participação no Pibid abre as seguintes possibilidades aos coordenadores de área: 1) repensar a formação que oferecem aos licenciandos, tanto no contexto de suas próprias práticas quanto no contexto institucional; 2) transformar suas práticas formativas com base nessas reflexões; 3 ) incorporar resultados obtidos por meio das ações do Pibid aos seus trabalhos de pesquisa.

TEDESCO, Sirlei. Formação continuada de professores: experiências integradoras de políticas educacionais - PNAIC e Prouca - para alfabetização no ensino fundamental de uma escola pública. 2015. 93 f. Dissertação (mestrado em Educação) - Pontifícia Universidade Católica do Rio Grande do Sul, 2015. Disponível em: < http://hdl.handle. net/10923/7084>.

A pesquisa investiga de que maneira a formação continuada de professores alfabetizadores contribuiu para a melhoria da prática pedagógica, sob a orientação da política do Pacto Nacional pela Alfabetização na Idade Certa (PNAIC) e em contextos digitais providos pelo Programa Um Computador por Aluno (Prouca), em Fagundes 
Varela, no estado do Rio Grande do Sul. O processo iniciou-se em 2012 com a adesão ao Prouca e, em 2013, houve a adesão ao PNAIC com o plano para formação dos professores, objetivando promover a alfabetização mediante suporte tecnológico do Prouca. A abordagem metodológica foi baseada em observações, questionário e análise documental, utilizando-se a análise textual discursiva. Verificou-se que os docentes mostraram comprometimento com o ato de ensinar e aprender, de maneira reflexiva, inovadora e qualitativa pela inserção das tecnologias digitais, e com o novo olhar para a aprendizagem de alunos no ciclo de alfabetização. Os resultados demonstraram-se positivos e satisfatórios na opinião dos professores que efetivamente fizeram parte das formações do Prouca e do PNAIC, considerando esses programas instrumentos que auxiliam no desenvolvimento de competências e potencialidades para qualificar o fazer pedagógico nos anos iniciais do ensino fundamental.

VOLSI, Maria Eunice França. Políticas de valorização de professores da educação básica pós-Constituição Federal de 1988. 209 f. Tese (doutorado em Educação) Universidade Estadual de Maringá, 2016. Disponível em: <http://www.ppe.uem.br/ teses/2016/2016\%20-\%20Maria\%20Eunice\%20Franca\%20Volsi.pdf>.

As políticas e ações desenvolvidas com a finalidade de promover a valorização de professores da educação básica brasileira, no período 1988 a 2014, foram investigadas a fim de verificar se evidenciam compromisso com a concretização desse preceito. A pesquisa foi desenvolvida com base na ciência da história por se entender que as políticas destinadas à área da educação - e especificamente à subárea em questão - são fruto das necessidades criadas pelos homens no processo de produção da vida material. Isso não significa, no entanto, que essas políticas correspondam às reais necessidades dos homens, mas sim às necessidades de manutenção do sistema capitalista em sua atual conjuntura. São apresentadas as orientações internacionais das agências Banco Mundial e Organização para Cooperação e Desenvolvimento Econômico (OCDE), que têm contribuído para a constituição das políticas educativas, em especial a de valorização de professores. Discorre-se sobre os pressupostos históricos e políticos no desenrolar do processo de elaboração dessas políticas, bem como sua motivação e finalidade. Destacam-se os aspectos econômicos que determinaram não apenas o seu processo de elaboração, como também as próprias políticas e, portanto, as orientações e ações a serem desenvolvidas na educação básica brasileira. Apresentam-se as políticas de valorização de professores pós-Constituição de 1988 nos cinco governos ao longo desses 26 anos e a legislação que estabeleceu e regulamentou as políticas de valorização de professores nesse período. Nas considerações finais, são sinalizados os desafios que permanecem para a construção e concretização das políticas de valorização de professores no Brasil. 
YAMASHIRO, Carla R. C. A emergência da necessidade formativa docente no campo discursivo da formação de professores no Brasil. 2014. 260 f. Tese (doutorado em Educação) - UNESP, Faculdade de Ciências e Tecnologia, campus de Presidente Prudente, 2014. Disponível em: < http://www2.fct.unesp.br/pos/educacao/teses/2014/ dr/carla_yamashiro.pdf>.

O interesse pela emergência da necessidade formativa de professores no discurso da formação de professores no Brasil surgiu a partir de leituras de textos de Michel Foucault sobre o nexo entre a produção de saber e o exercício do poder e seus efeitos na subjetivação do indivíduo e na regulação da população e a partir de leituras sobre a produção do discurso como arena do exercício do poder e da estratégia de governamento. Os objetivos específicos da pesquisa são: 1) identificar, descrever e analisar os regimes de verdade produzidos pelos discursos do âmbito da legislação educacional, mais especificamente da política para formação continuada de professores no Brasil, que colocam a análise de necessidades da formação dentro da ordem do discurso da política para formação de professores; 2) compreender quais são os efeitos provocados pelo exercício do poder biopolítico no discurso da formação de professores na atual política para formação de professores. A metodologia corresponde à análise discursiva de textos articuladores das políticas brasileiras para formação de professores, mediante a norma, a função-autor e o comentário. A análise indicou que a emergência da necessidade de formação docente coexiste com a emergência de outros objetos, como a inclusão de todos na educação escolar e aprendizagem permanente como estratégia biopolítica de subjetivação do indivíduo professor e de sua população em um tipo de sujeito homo oeconomicus da educação. 